\title{
Interdecadal Changes in Atmospheric Low-Frequency Variability with and without Boundary Forcing*
}

\author{
A. W. Robertson AND M. GHIL \\ Department of Atmospheric Sciences and Institute of Geophysics and Planetary Physics, \\ University of California, Los Angeles, Los Angeles, California \\ M. LATIF \\ Max-Planck-Institut für Meteorologie, Hamburg, Germany
}

(Manuscript received 6 October 1997, in final form 25 May 1999)

\begin{abstract}
The response of the Max Planck Institute's ECHAM3 atmospheric general circulation model to a prescribed decade-long positive anomaly in sea surface temperatures (SSTs) over the North Atlantic is investigated. Two 10-yr realizations of the anomaly experiment are compared against a 100-yr control run of the model with seasonally varying climatological SST using a model spatial resolution of T42. In addition to the time-mean response, particular attention is paid to changes in intraseasonal variability, expressed in terms of North AtlanticEuropean weather regimes. The model regimes are quite realistic.

Substantial differences are found in the 700-mb geopotential height field response between the two decadal realizations. The time-mean response in the first sample decade is characterized by the positive (zonal) phase of the North Atlantic oscillation (NAO); this response can be identified with changes in the frequency of occurrence of certain weather regimes by about one standard deviation. (Preliminary results of this numerical experiment were reported at the Atlantic Climate Variability Workshop held at the Lamont-Doherty Earth Observatory of Columbia University, Palisades, New York, 24-26 September 1997.) By contrast, the second SST anomaly decade shows a localized trough centered over the British Isles; it projects less strongly onto the model's intrinsic weather regimes. The control run itself exhibits pronounced decade-to-decade variations in the weather regimes' frequency of occurrence as well as in its NAO index. The two 10-yr anomaly experiments are insufficient, in length and number, to identify a robust SST response above this level of intrinsic variability.
\end{abstract}

\section{Introduction}

The atmospheric response to North Atlantic sea surface temperature (SST) anomalies is still not well documented nor clearly understood. In studies of observed data, significant correlations have been found between SST and the North Atlantic oscillation (NAO) teleconnection pattern (e.g., Wallace et al. 1990). The simultaneous character of these correlations suggests largescale ocean-atmosphere interaction. Surface wind anomalies exert a large and well-known influence on SSTs through evaporation. Ekman transport, and ocean mixing (e.g., Frankignoul 1985).

\footnotetext{
*Institute of Geophysics and Planetary Physics Publication Number 4996.

Corresponding author address: Dr. Andrew W. Robertson, Department of Atmospheric Sciences, UCLA, 405 Hilgard Avenue, Los Angeles, CA 90095-1565.

E-mail: andy@atmos.ucla.edu
}

Several general circulation model (GCM) studies have attempted to determine the effect of North Atlantic SST anomalies on the atmospheric circulation, but the results have been ambiguous. Palmer and Sun (1985) *Institute of Geophysics and Planetary Physics Publication Number 4996. found an equivalent barotropic ridge either collocated with or downstream of a warm SST anomaly, while Peng et al. (1995) report a positive GCM height response in a perpetual November experiment but a negative height anomaly using perpetual January conditions. Kushnir and Held (1996) argue for yet another type of response, a shallow trough downstream of a prescribed warm SST anomaly.

The western North Atlantic is a region of vigorous cyclogenesis, associated with strong surface temperature gradients. SST anomalies directly affect these thermal gradients, and thus have the potential to influence the growth of baroclinic eddies and the North Atlantic storm track. On intraseasonal timescales, changes in the position and intensity of the latter are known to be intimately related to persistent and recurrent large-scale 
circulation patterns (Lau 1988; Metz 1991) or weather regimes (Robertson and Metz 1990; Robertson and Ghil 1999).

These regimes have fixed geographical patterns and a typical duration of 7-15 days (Dole and Gordon 1983; Mo and Ghil 1988; Molteni et al. 1990; Vautard 1990; Cheng and Wallace 1993; Kimoto and Ghil 1993a,b), and transitions between them are associated with the nonlinearity of atmospheric dynamics. Pursuing this line of reasoning, a decadal SST anomaly over the North Atlantic can be expected to generate a bias in the statistics of the atmosphere's intrinsic weather regimes (Ghil and Childress 1987, section 6.5; Palmer 1993) rather than a linear response to a prescribed anomalous thermal source. Observed atmospheric variability over the North Pacific associated with El Niño has been interpreted in this way (Horel and Mechoso 1988; Kimoto 1989, Fig. 64 there; Robertson and Ghil 1999).

The aim of the present paper is to analyze the response of an atmospheric GCM to a North Atlantic SST anomaly during winter in terms of 1) conventional differences in time means and 2) changes in the frequency distribution of North Atlantic-European weather regimes (Rheinhold and Pierrehumbert 1982)_or, more precisely, large-scale flow regimes (Legras and Ghil 1985) - that the SST anomaly might give rise to. In the latter case, the question of statistical significance shifts from the difficult and highly underdetermined multivariate problem of assessing the change in response pattern to the potentially more tractable one of assessing changes in frequency of occurrence for a small number of regimes. The atmospheric response is thus assumed, a priori, to be describable in terms of a small set of (nonorthogonal) patterns, namely, the model's intrinsic weather regimes. Should the response project strongly onto these, we stand to greatly reduce the dimensionality of the problem and increase the signal-to-noise ratio. This strategy bears similarities to the "guess pattern", hierarchy proposed by Hasselmann (1979).

Ultra-low-frequency variability due to purely internal atmospheric processes has been suggested by a number of authors as an important source of climate variability (James and James 1989; Lorenz 1990; Held 1993; Marshall and Molteni 1993). A second goal of the present paper is to quantify the GCM's intrinsic variability over the North Atlantic in terms of intraseasonal weather regimes, constructed from a 100-yr control run of the model with climatological SSTs prescribed. This intrinsic variability is compared with the forced response to the SST anomalies.

In section 2 we describe the model experiments and data preparation. Weather regimes are constructed in section 3 and used to interpret the interdecadal variability intrinsic to the atmosphere in the control run, and the forced response to a North Atlantic SST anomaly in the two response experiments. Concluding remarks follow in section 4 .

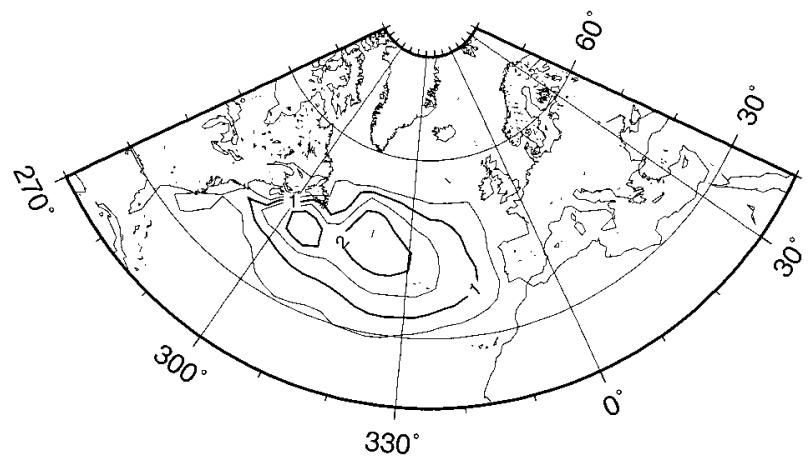

FIG. 1. Prescribed sea surface temperature anomaly $\left({ }^{\circ} \mathrm{C}\right)$. Contour interval is $0.5^{\circ} \mathrm{C}$.

\section{Model experiments and data preparation}

In this study we use the ECHAM3 atmospheric GCM of the Max Planck Institute for Meteorology in Hamburg, Germany, with a spatial resolution of T42 (Roeckner et al. 1992; Bengtsson et al. 1996). The model integrations consist of a 100-yr control run with prescribed seasonally varying climatological SSTs and two 10-yr anomaly experiments. The second anomaly experiment was simply run as a continuation of the first. A positive SST anomaly derived from observations was added over the North Atlantic in each anomaly experiment; its large-scale pattern covers the Gulf Stream extension between about $30^{\circ}$ and $50^{\circ} \mathrm{N}$ (Fig. 1). Meridional SST gradients peak in this region, which coincides with the southern flank of the Atlantic storm track.

The anomaly pattern was derived from an empirical orthogonal function (EOF) analysis of SSTs for individual calendar months by Y. Kushnir (1996, personal communication). The particular EOF chosen dominates the fall and early winter, and its time series shows a strong decadal component. The pattern resembles the quasi-decadal SST fluctuation of Deser and Blackmon (1993); more precisely, Moron et al. (1998) find such a pattern as the extreme warm phase of their 7-8-year oscillation. To enhance the signal-to-noise ratio, the magnitude of the observed anomaly was multiplied by 5 , giving a maximum amplitude of about $+2{ }^{\circ} \mathrm{C}$.

We analyze the model's 90-day winters of daily 700$\mathrm{mb}$ heights over the North Atlantic-European sector $\left(20^{\circ}-60^{\circ} \mathrm{N}, 90^{\circ} \mathrm{W}-40^{\circ} \mathrm{E}\right)$, starting on 1 December and low-pass filtered with a half-power point at 10 days (Blackmon and Lau 1980). The original height data are given on the model's approximately $2.8^{\circ}$ latitude by $2.8^{\circ}$ longitude Gaussian grid. The control run comprises 99 winters, for a total of 8910 days. To obtain as many winter days as possible from each 10-yr anomaly experiment, we include January and February of year 1 and December of year 10, minus 9 days in each case because of the low-pass filtering; this yields a total of 882 days. The boreal winter interval of study is referred to as December-January-February (DJF).

The mean seasonal cycle of the control run was cal- 
culated, day by day, from the 99 years of low-pass filtered data. This cycle was subtracted at the outset from both the control and the SST anomaly experiments. Prior to computing EOFs, the gridpoint data were weighted by the square root of the cosine of latitude, following Branstator (1987).

\section{Weather regimes}

We define weather regimes in terms of local maxima in the model atmosphere's probability density function (PDF), constructed in the subspace of the four leading EOFs of low-pass filtered 700-mb height maps over the North Atlantic sector. Bumps in the PDF correspond to recurrent and persistent height patterns in physical space. The PDF is obtained from the position of the 8910 maps in the four-dimensional subspace above by using a kernel density estimator. This estimator provides a trade-off between smoothness and robustness to subsampling of the PDF, on the one hand, and fidelity to the data, on the other.

We apply the iterative bump-hunting method employed by Kimoto and Ghil (1993b, KG hereafter) to find the local maxima of the PDF so obtained. An angular metric is used, in which length corresponds to pattern correlation between North Atlantic height fields in physical space. Since there is no unique or optimal definition of planetary flow or weather regimes, we rely on the $K$-means or dynamical clustering method (MacQueen 1967) as applied by Michelangeli et al. (1995, MVL hereafter) to test the robustness of our bump-hunting results.

\section{a. The control run}

The four leading covariance matrix EOFs over the North Atlantic sector account for $71 \%$ of the variance in the low-pass filtered daily 700-mb height data. Six regimes were obtained from the 99 winters of the control run using a smoothing parameter of $h=40^{\circ}$ for the estimating kernel. Figure 2 displays composite hemispheric maps of low-pass filtered daily 700-mb heights for the days belonging to each regime; $42 \%$ of all days are classified. Daily maps are assigned to a given cluster if they have a pattern correlation of 0.82 or greater with that cluster's central map; this produced clusters with negligible overlap.

The patterns are robust when comparing results obtained separately for the first and second half of the dataset. With a larger smoothing parameter $\left(h=50^{\circ}\right)$, one obtains only four regimes $(1,2,3$, and 6$)$, but these are less robust to dividing the time series into two halves. Values of $h>50^{\circ}$ reduce the number still further, while the dependence of the number of clusters on $h$ is small for values of $h$ around $40^{\circ}$, hence the choice of this value as the most robust one. Similar regime composite patterns were obtained using the $K$-means method when choosing a priori the method's number $K$ of clus- ters as $K=6$ : the pattern correlations $r$ between the PDF regimes and their $K$-means counterparts are given in the caption of Fig. 2 and are quite high, ranging from 0.82 to 0.99 .

Regimes 1 and 3 appear to correspond to the model's NAO and have close counterparts in observed analyses (cf. Barnston and Livezey 1987; Cheng and Wallace 1993). Regime 1 has more of a NW-SE orientation than the classic NAO pattern, and Barnston and Livezey (1987) find this pattern to be more pronounced during February than in December-January. Regime 2 resembles the east Atlantic pattern of Barnston and Livezey (1987), while regimes 4 and 5 are similar to Vautard's (1990) Atlantic ridge and zonal weather regimes, respectively. Close counterparts of ECHAM3 regimes 1-3 are found in the observed regimes of KG and MVL.

Pattern correlations with the five regimes derived from an identical bump-hunting analysis of 44 winters (1951-95) of observed daily 700-mb heights from the National Centers for Environmental Prediction are 0.72, $0.89,0.91,0.77,0.75$, and 0.37 for each regime in Fig. 2 , respectively. The control run's regimes are thus encouragingly realistic, given that we are dealing with a GCM in which no interannual SST variations are included.

\section{b. The SST anomaly experiments}

We now investigate the extent to which the regimes of the control run occur in the two 10-yr anomaly experiments-referred to as decades 1 and 2, respectively, in the following-and how their frequency of occurrence differs compared to the model's intrinsic interdecadal variability. Preliminary results for decade 1 were reported by Robertson et al. (1998). The 882 lowpass filtered daily maps from each anomaly experiment were projected onto the four leading EOFs of the control experiment, and we counted the number of days falling into each of the control run's regimes. These counts are plotted in Fig. 3 for anomaly decade 1 (solid triangles) and decade 2 (inverted triangles). The analogous counts for each of the 10 control decades are plotted in terms of their mean (open circles) and standard deviation $\sigma$ (shown as a two-sided error bar).

In decade 1 , three regime-frequency changes are about $1 \sigma$ in magnitude, with regime 1 (Greenland cyclone) being more prevalent and regimes 3 (Greenland anticyclone) and 6 occurring less often in the SST anomaly experiment. The frequencies of occurrence for regimes 2, 4, and 5 are close to the control experiment's corresponding mean frequencies; the likelihood of these regimes does not seem to be appreciably influenced by the SST anomaly. The total number of days in the first SST anomaly experiment that fall within the bump-hunting clusters of Fig. 2 is $39.7 \%$; this is very close to the corresponding number of $42.1 \%$ that is so classified in the 99 winters of the control run. It follows that the control clusters are visited just as often in anomaly de- 
cade 1 as in the control experiment. Very similar results were found when using the $K$-means method with $K=$ 6 . In decade 2 , there is a tendency toward regime 5 (zonal flow) at the expense of regime 4 (Atlantic ridge), both with frequency changes of about $1 \sigma$. Here $40.6 \%$ of the days fall into the control clusters, even closer to the percentage so classified in the control run.

The character of the model's intraseasonal variability is relatively insensitive to the North Atlantic SST anomaly in terms of the total number of days in each anomalyresponse experiment that fall into the control run's weather regimes. To estimate possible changes in the regimes' spatial structure, the bump-hunting method was applied to the two anomaly-experiment decades concatenated together, using the same smoothing parameter, $h=40^{\circ}$.

Six regimes were found (not shown), in which the pattern correlations with the control-regime composites are 0.97 (3), 0.88 (4), 0.79 (1), 0.78 (2), 0.73 (3), and 0.72 (1); the number in brackets denotes the control regime with which the respective anomaly regime is best correlated. Thus, anomaly-run regimes 1 and 5 are both close to control-run regime 3 , while anomaly-run regimes 3 and 6 are both close to control-run regime 1, and no anomaly-run regime is close to either controlrun regime 5 or 6 . Although it is difficult to estimate weather regimes robustly with only 20 winters of data, the control regimes 1-4 are recovered independently from the anomaly experiments with pattern correlations exceeding 0.7 .

As a further test of pattern similarity, we have computed (using $K$-means and the "classifiability" methodology of MVL) the similarity between regime patterns derived from each decade of the control run in turn and those of the other control-run decades. The interdecadal variability in the patterns derived from the control run was found to be just as large as the difference between the control run and the SST anomaly experiments.

\section{c. Weighted-mean and overall-mean response}

We saw that the control regimes, computed from a century of GCM results, are specified fairly robustly by the composite maps in Fig. 2. These composite anomalies are defined with respect to the overall mean of the control experiment. The model atmosphere's response to the SST anomaly can thus be characterized-as an alternative to the simple time-mean response-by each regime's mean anomaly, weighted by the ratio of the frequency of occurrence in the respective response experiment relative to the control experiment; the two frequencies in question are denoted, respectively, by the solid triangles and open circles in Fig. 3. These regimecomposite responses are illustrated in Fig. 4, while Fig. 5 shows the conventional 700-mb geopotential height response for each anomaly experiment in terms of the respective difference in time mean from the control run.

The regime response in decade 1 (Fig. 4a) consists of relatively more of regime 1 and less of regimes 3 and 6 and resembles quite closely the positive phase of the classic NAO teleconnection pattern (cf. Hurrell 1995). Over the North Atlantic, the pattern is similar in amplitude to the difference in time means (Fig. 5a), with a ratio of $10-20 \mathrm{gpm} \mathrm{K}^{-1}$ of SST anomaly, but is much more localized.

The difference in time means exhibits a hemispheric pattern with a strong zonally symmetric component. Regions of statistical significance are stippled in Fig. 5 at the $95 \%$ level, according to a two-sided Student's t-test of 882-day means. Few grid points are significant at this level, and the response is apparently more significant over the Pacific than the Atlantic. The difference in time means is largely equivalent barotropic in the vertical, but the trough centered north of Iceland at $700 \mathrm{mb}$ extends southward to near $40^{\circ} \mathrm{N}$ at sea level (not shown).

The regime-weighted response in decade 2 (Fig. 4b) is quite different from decade 1: it contains more of regime 5 and less of regime 4 . It consists predominantly of a 700-mb trough centered over the British Isles, well downstream of the SST anomaly. The regime-weighted response is again similar to the overall-mean response (Fig. 5b), but it is weaker and reaches about $10 \mathrm{gpm}$ only over the British Isles. The difference in time means for decade 2 is generally even less significant than for decade 1 , while the pattern in mean sea level pressure (not shown) is similar, but with the trough centered just west of Ireland. Neither experiment exhibits a significant 700-mb height response over the SST anomaly itself.

\section{d. Interdecadal variability of the $N A O$}

The response to a North Atlantic SST anomaly is NAO-like in decade 1 but nearly in spatial quadrature with the NAO in decade 2 . Indeed, the regime-weighted responses (Figs. 4a,b) resemble the two leading EOFs of observed mean sea level pressure over the North Atlantic sector (not shown). This suggests that each of the two EOFs points in a direction of phase space populated by a particular subset of weather regimes (Mo and Ghil 1988) and that the initial state of a particular simulation might lead preferentially in one or the other of these two directions (Vautard et al. 1990; KG), even when the model is subjected to lower-boundary forcing that differs from climatology.

The decadal evolution of a Greenland-Azores NAO index in the control run is illustrated in Fig. 6, in terms of $10-\mathrm{yr}$ running means. The noisy nature of the latter is due to the large interannual standard deviation (61.6 $\mathrm{m})$. The model's NAO index does undergo interdecadal excursions, but these only exceed the $90 \%$ confidence level of white noise fluctuations for two out of the run's 10 decades. The error bars for the 5 and 95 percentiles in the figure were constructed by repeatedly drawing random subsets of 10 winters from the 99 winters of the control run. The power spectrum of the control run's 
a) $\operatorname{Reg} 1(698) \quad 180^{\circ}$

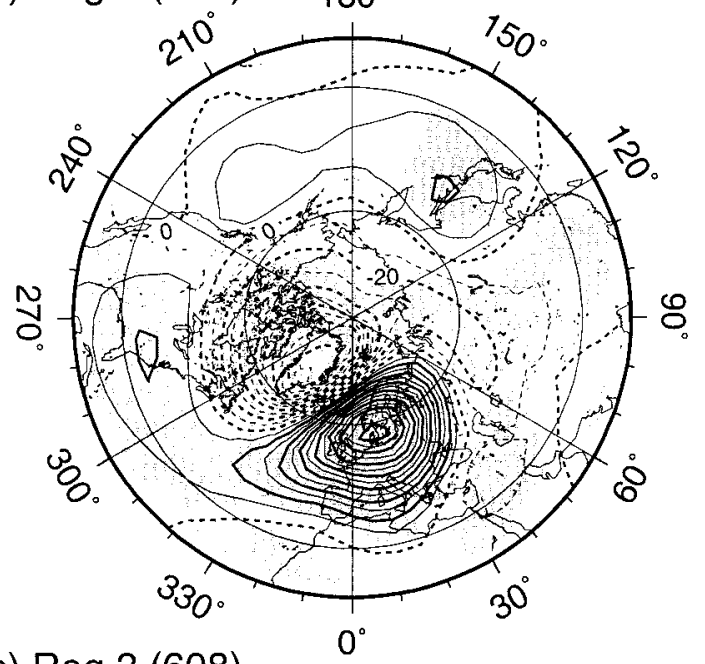

c) $\operatorname{Reg} 3$ (608)

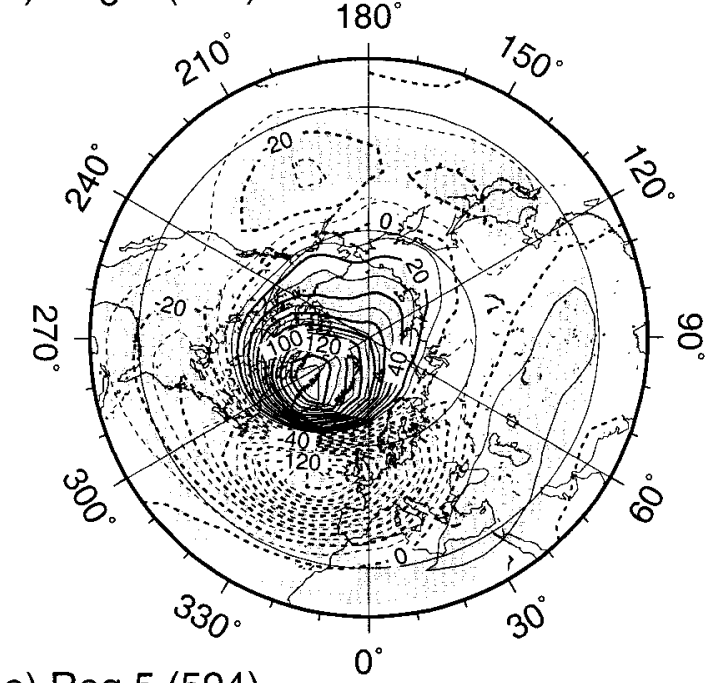

e) Reg 5 (594)

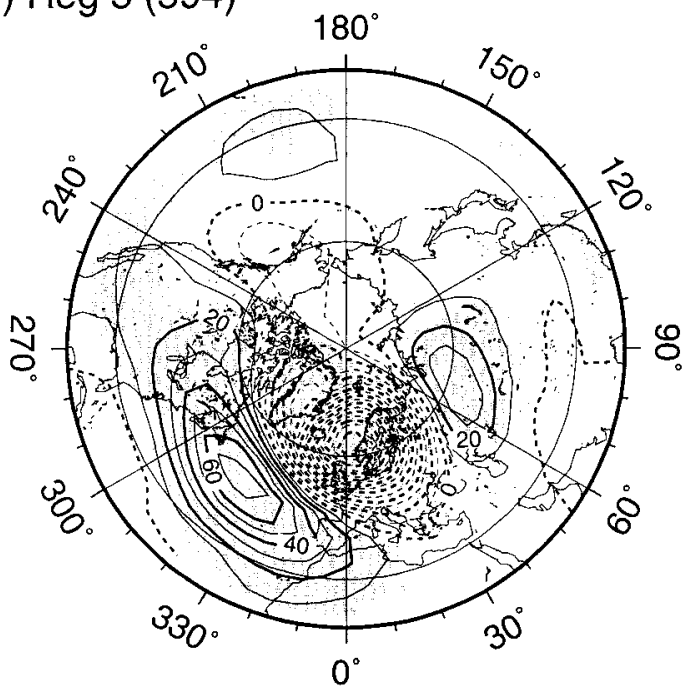

b) $\operatorname{Reg} 2(683) \quad 180^{\circ}$
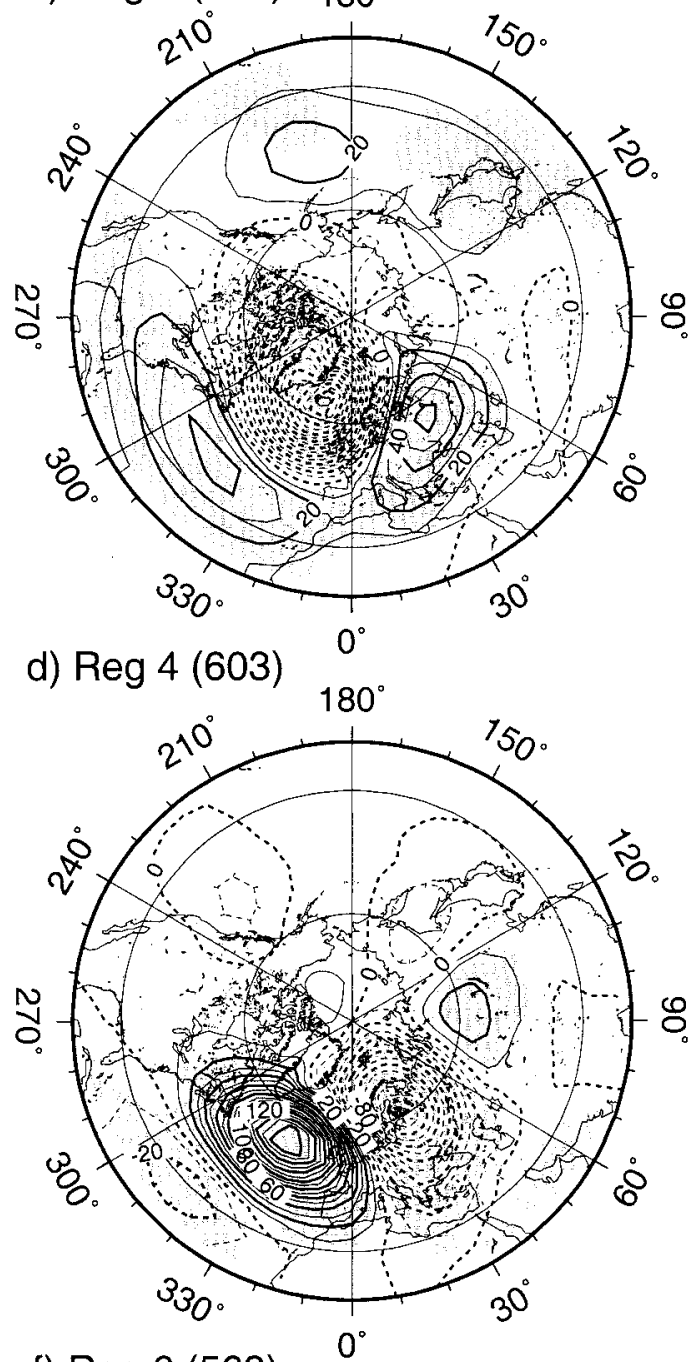

f) $\operatorname{Reg} 6$ (568)

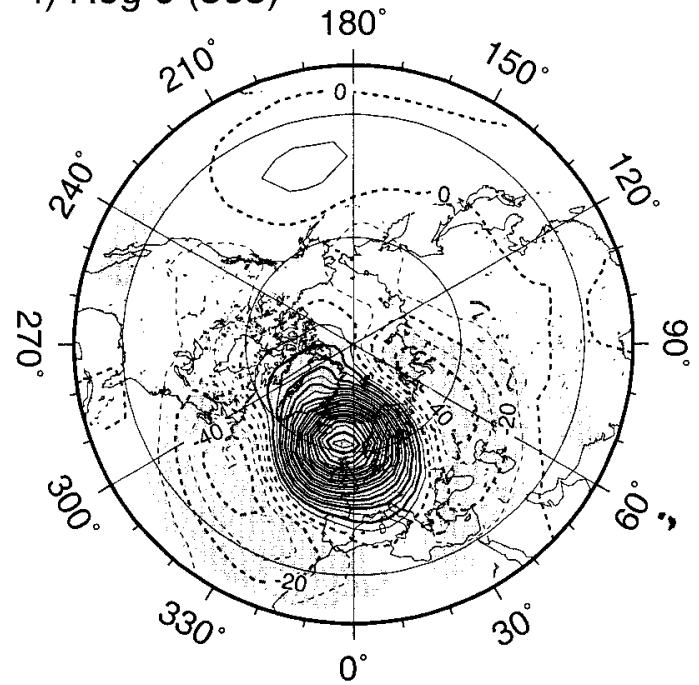

FIG. 2. Weather regimes of the control experiment over the North Atlantic-European sector derived using KG's bump-hunting method. Each map is a composite of low-pass filtered 700-mb height anomalies (gpm) on days belonging to that regime; contour interval is $10 \mathrm{gpm}$. Shaded region indicates areas significant at the $95 \%$ level using a two-tailed Student's t-test. The regimes 
NAO index (not shown) does not deviate significantly from a white spectrum. Thus, there is no substantial excess power in the interdecadal band, in contrast to that found in the model of James and James (1989).

The triangle and inverted triangle superposed on Fig. 6 denote the ECHAM3 model's NAO index averaged over decades 1 and 2, respectively, of our SST anomaly experiments. The NAO projection of the SST anomaly response in decade 1 has a slightly higher level of statistical significance than the regime projections in Fig. 3 ; this is consistent with the NAO-like regime-composite response in Fig. 4a (see also the discussion of minimal representation of sectorial PDFs in Smyth et al. 1999).

\section{Concluding remarks}

We have shown that a limited sample of two 10-winter runs is insufficient to identify a robust atmospheric response in the ECHAM3 atmospheric GCM to a typical pattern of North Atlantic decadal SST variability (Deser and Blackmon 1993; Moron et al. 1998). This is the case in terms of the time-averaged 700-mb DJF geopotential height field, as well as for the statistics of intraseasonal weather regimes.

The two 10-yr realizations of our SST anomaly experiment were found to yield rather different $700-\mathrm{mb}$ geopotential height responses: the first projects strongly onto the NAO pattern, while the second consists of a trough well downstream of the prescribed SST anomaly. Neither of these responses was found to be significant with a high level of statistical confidence, compared to the model's intrinsic interdecadal variability in the 100yr control run. This negative result is consistent with the current lack of consensus in the published literature regarding the atmospheric response to North Atlantic SST anomalies.

The SST anomaly response in both 10 -yr runs was shown to be associated with changes of about $1 \sigma$ in the frequency of occurrence of a subset of the model's six intraseasonal weather regimes. Although the 99 winters of the control run were used to construct these regimes, the anomaly runs are too short or too few to allow us to obtain statistical confidence in these frequency-of-regime occurrence changes.

Our results suggest that the spatiotemporal NAO pattern is made up of two or three distinct weather regimes. Cheng and Wallace (1993) have pointed out already that the NAO may be the result of differencing between two spatially asymmetric weather regimes and similar asymmetries between "opposite phases" of the Pacific-North American pattern - as well as indirect transitions via a third regime between them-have been pointed out by

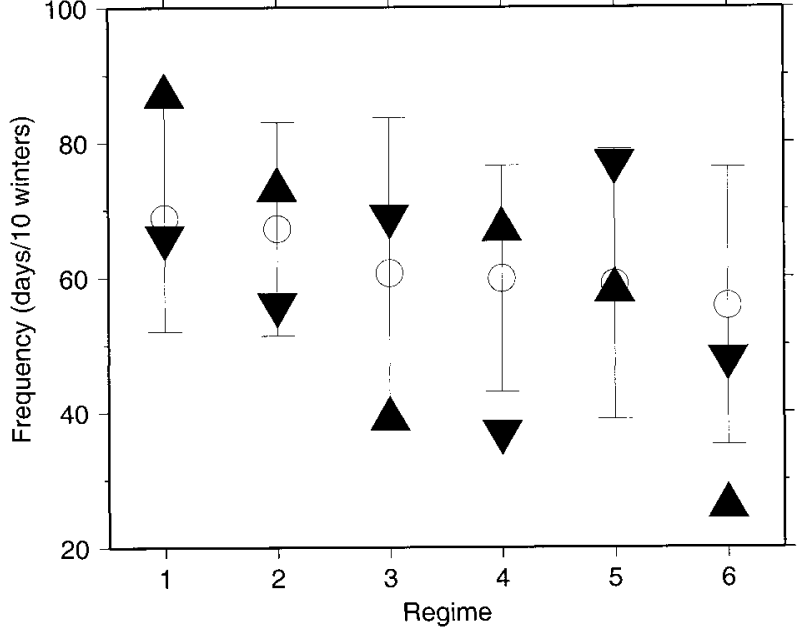

FIG. 3. Frequency of occurrence of a daily map within each of the six control (PDF) clusters in decade 1 (solid triangles) and decade 2 (inverted triangles) of the SST anomaly experiment. Open circles and error bars show the mean frequency of occurrence and $1 \sigma$ on either side for the six regimes in the 10 non-overlapping 882-day control decades.

Mo and Ghil (1988) and KG. The control run itself shows pronounced interdecadal excursions in the weather regime frequency and the NAO index, but these were found to be distinguishable only marginally from white noise.

We have repeated the regime analysis using a hemispheric domain. In this case, four PDF regimes were obtained, but these did not prove to be robust with respect to details of the method. Two of these hemispheric regimes (not shown) were found, however, to resemble opposing polarities of the time-mean SST anomaly response in decade 1 shown in Fig. 5a. Projecting this response onto the two hemispheric regimes analogously to Fig. 4 yields a statistically significant response at the $95 \%$ level. It would thus appear that the GCM does have a hemispheric mode of variability with a large degree of zonal symmetry, and that this is preferentially excited by a North Atlantic SST anomaly during decade 1. Hemispheric regime analyses of observed data by Cheng and Wallace (1993) and Smyth et al. (1999) suggest that coherent modes of hemispheric variability may exist in the atmosphere and that they have preferred sectorial manifestations. Kitoh et al. (1996) and Thompson and Wallace (1998) also present observational evidence of a hemispheric mode in the troposphere that is related to interannual variations in the stratospheric polar vortex.

The NAO-like response in the first SST anomaly experiment might be interpreted as the excitation of an

$\leftarrow$

are ranked according to the number of days belonging to each regime, given in brackets. Pattern correlations with regimes derived using MVL's $K$-means method are $0.82,0.89,0.99,0.95,0.91$, and 0.93 , respectively. 

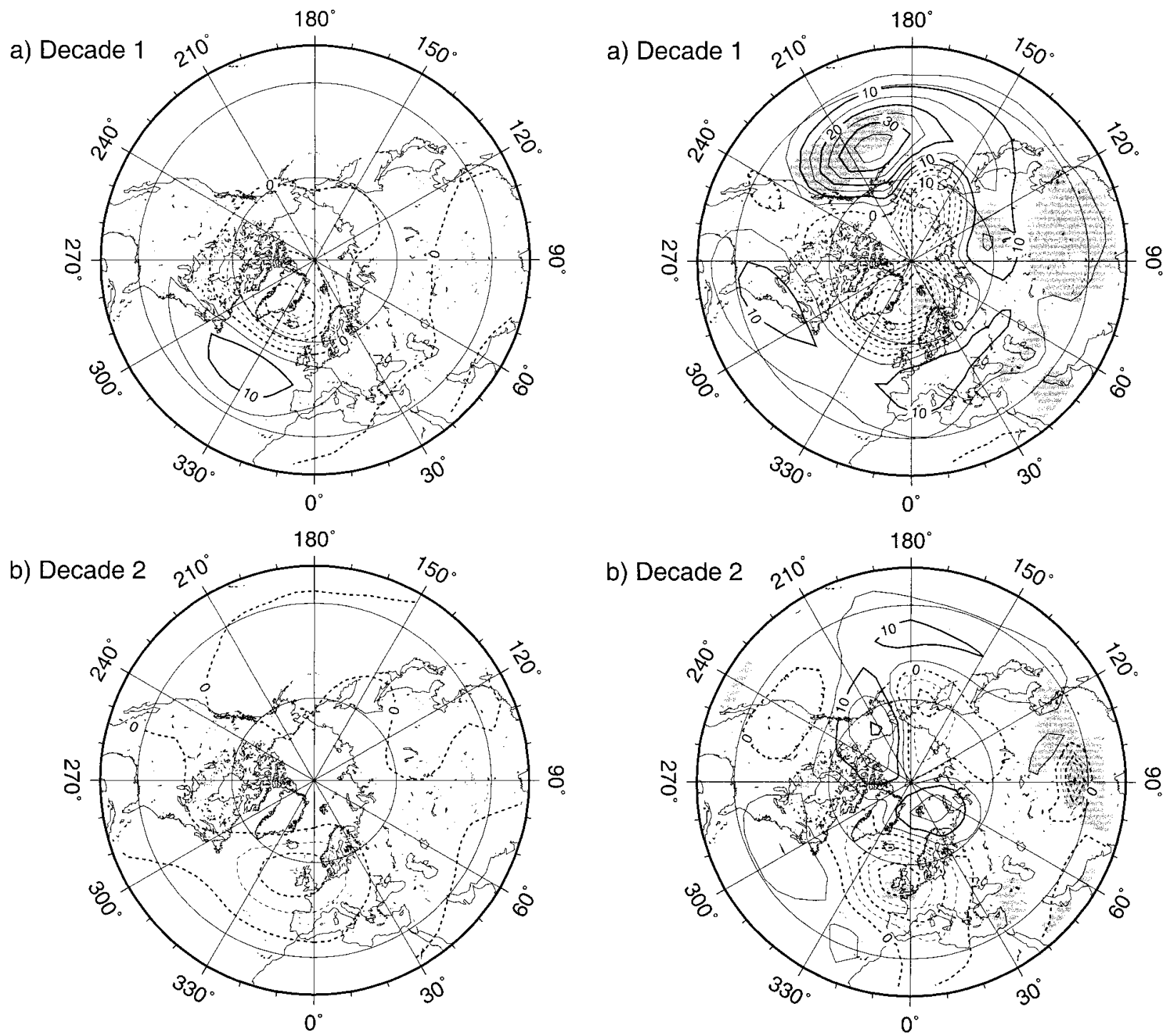

FIG. 4. Weather regime response to SST anomaly constructed by weighting the six maps in Fig. 2 by the frequency ratios between each anomaly decade and the control experiment in Fig. 3: (a) decade 1 and (b) decade 2. Contour interval is $5 \mathrm{gpm}$.

equivalent barotropic internal mode of possibly hemispheric extent that may, or may not, be influenced by the underlying SST anomaly. At sea level, the responses in the two anomaly experiments do resemble each other better, as they both show a surface trough downstream of the SST anomaly. This shallow baroclinic low may represent the only robust feature of the model's response. Some support for this interpretation comes from the GCM study of Kushnir and Held (1996), who also found a shallow low situated downstream of a warm SST anomaly over the North Atlantic, while the equivalent barotropic response was not robust.

Grötzner et al. (1998) have coupled the same ECHAM3 atmospheric GCM considered here to the Hamburg ocean primitive-equations model. They find a

FIG. 5. Mean DJF 700-mb height response for (a) decade 1 and (b) decade 2 of the SST anomaly experiment. Shown is the mean of each 10-winter SST response experiment, minus the mean of the 99winter control experiment. Contour interval is $5 \mathrm{gpm}$. Shaded region indicates areas significant at the $95 \%$ level using a two-tailed Student's t-test.

17-yr cycle in which a broad positive North Atlantic SST anomaly, situated slightly farther south than ours, is associated with an anomaly in the NAO that resembles the one found here in decade 1 . This, together with the absence of a definite response in our uncoupled study, suggests that coupled ocean-atmosphere interaction may play an important role in the atmospheric response to SST anomalies over the North Atlantic on decadal timescales.

Acknowledgments. We would like to thank Drs. Y. Kushnir and E. Roeckner for providing the data of the SST anomaly and control integrations, respectively, and 


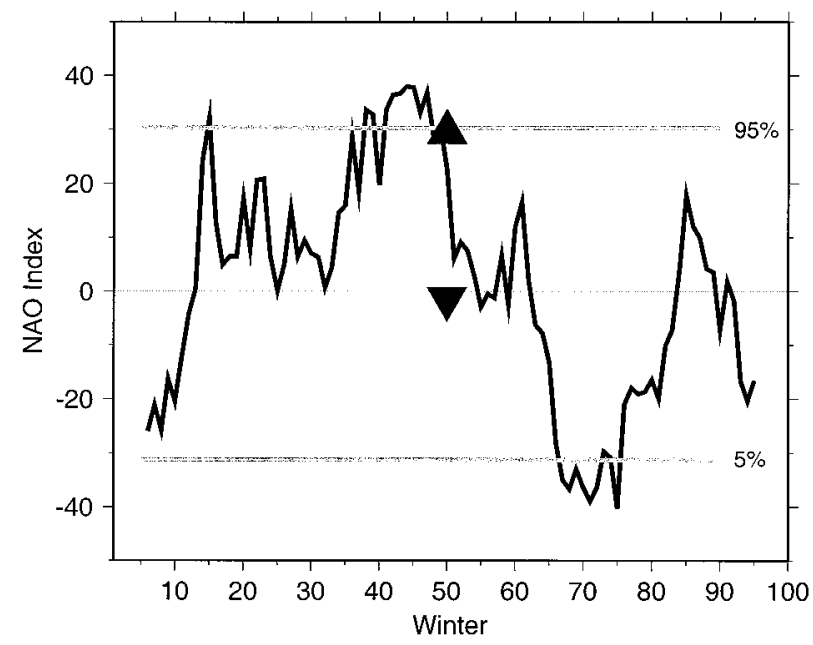

FIG. 6. The time evolution of the model's NAO index, defined as the difference in 700-mb geopotential height between Greenland $\left(60^{\circ}-80^{\circ} \mathrm{N}, 20^{\circ}-60^{\circ} \mathrm{W}\right)$ and the Azores $\left(30^{\circ}-45^{\circ} \mathrm{N}, 10^{\circ}-60^{\circ} \mathrm{W}\right)$ Shown are 10 -yr running means of the control experiment (solid line), together with decade 1 (solid triangle) and decade 2 (inverted triangle) of the anomaly experiment. The gray horizontal lines denote the 5 and 95 percentiles of the NAO index constructed from 1000 randomly shuffled samples of 10 winters from the control run.

S. Koo for assistance in implementing the $K$-means algorithm. Constructive comments from three anonymous referees helped improve the presentation. AWR wishes to acknowledge the Max Planck Institute for its hospitality during the summer of 1996, when this work was initiated. AWR's work is supported by DOE Grant DEFG03-98ER62615 and the University of California's Campus Laboratory Collaboration (CLC) program. MG's work is partially supported by an NSF Special Creativity Award and NASA Grant NAG 5-713. ML's work was sponsored by the "PROVOST" project of the European Union and the "Klimavariabilitaet und Signalanalyse" project of the German government. The GCM integrations were performed at the Deutsches Klimarechenzentrum in Hamburg.

\section{REFERENCES}

Barnston, A. G., and R. E. Livezey, 1987: Classification, seasonality, and persistence of low-frequency atmospheric circulation patterns. Mon. Wea. Rev., 115, 1083-1126.

Bengtsson, L., K. Arpe, E. Roeckner, and U. Schulzweida, 1996: Climate predictability experiments with a general circulation model. Climate Dyn., 12, 261-278.

Blackmon, M. L., and N.-C. Lau, 1980: Regional characteristics of the Northern Hemisphere wintertime circulation: A comparison of the simulation of a GFDL general circulation model with observations. J. Atmos. Sci., 37, 497-514.

Branstator, G. W., 1987: A striking example of the atmosphere's leading traveling pattern. J. Atmos. Sci., 44, 2310-2323.

Cheng, X., and J. M. Wallace, 1993: Cluster analysis of the Northern Hemisphere wintertime 500-hPa height field: Spatial patterns. $J$. Atmos. Sci., 50, 2674-2696.

Deser, C., and M. L. Blackmon, 1993: Surface climate variations over the North Atlantic ocean during winter: 1900-1989. J. Climate, 6, 1743-1754.
Dole, R. M., and N. M. Gordon, 1983: Persistent anomalies of the extratropical Northern Hemisphere wintertime circulation: Geographical distribution and regional persistence characteristics. Mon. Wea. Rev., 111, 1567-1586.

Frankignoul, C., 1985: Sea surface temperature anomalies, planetary waves, and air-sea feedback in middle latitudes. Rev. Geophys., 8, 233-246.

Ghil, M., and S. Childress, 1987: Topics in Geophysical Fluid Dynamics: Atmospheric Dynamics, Dynamo Theory and Climate Dynamics. Springer-Verlag, $485 \mathrm{pp}$.

Grötzner, A., M. Latif, and T. P. Barnett, 1998: A decadal climate cycle in the North Atlantic Ocean as simulated by the ECHO coupled GCM. J. Climate, 11, 831-847.

Hasselmann, K., 1979: On the signal-to-noise problem in atmospheric response studies. Meteorology of the Tropical Oceans, D. B. Shaw, Ed., Royal Meteorological Society, 251-259.

Held, I. M., 1993: Large-scale dynamics and global warming. Bull. Amer. Meteor. Soc., 74, 228-241.

Horel, J. D., and C. R. Mechoso, 1988: Observed and simulated intraseasonal variability of the wintertime planetary circulation. J. Climate, 1, 582-599.

Hurrell, J. E., 1995: Decadal trends in the North Atlantic Oscillation: Regional temperatures and precipitation. Science, 269, 676-679.

James, I. N., and P. M. James, 1989: Ultra-low frequency variability in a simple atmospheric model. Nature, 342, 53-55.

Kimoto, M., 1989: Multiple flow regimes in the Northern Hemisphere winter. Ph.D. thesis, University of California, Los Angeles, 210 pp. [Available from UCLA, Box 951575, Los Angeles, CA 90095-1575.]

—_, and M. Ghil, 1993a: Multiple flow regimes in the Northern Hemisphere winter. Part I: Methodology and hemispheric regimes. J. Atmos. Sci., 50, 2625-2643.

- , and - 1993b: Multiple flow regimes in the Northern Hemisphere winter. Part II: Sectorial regimes and preferred transitions. J. Atmos. Sci., 50, 2645-2673.

Kitoh, A., H. Koide, K. Kodera, S. Yukimoto, and A. Noda, 1996: Interannual variability in the stratospheric-tropospheric circulation in a coupled ocean-atmosphere GCM. Geophys. Res. Lett., 23, 543-546.

Kushnir, J., and I. M. Held, 1996: Equilibrium atmospheric response to North Atlantic SST anomalies. J. Climate, 9, 1208-1220.

Lau, N.-C., 1988: Variability of the observed midlatitude storm tracks in relation to low-frequency changes in the circulation pattern. J. Atmos. Sci., 45, 2718-2743.

Legras, B., and M. Ghil, 1985: Persistent anomalies, blocking, and variations in atmospheric predictability. J. Atmos. Sci., 42, 433471.

Lorenz, E. N., 1990: Can chaos and intransitivity lead to interannual variability? Tellus, 42A, 378-389.

MacQueen, J., 1967: Some methods for classification and analysis of multivariate observations. Proc. Fifth Berkeley Symp. Math. Statistics and Probability, L. M. LeCam and J. Neyman, Eds., University of California Press, 281-297.

Marshall, J., and F. Molteni, 1993: Toward a dynamical understanding of planetary-scale flow regimes. J. Atmos. Sci., 50, 1792-1818.

Metz, W., 1991: Optimal relationship of large-scale flow patterns and the barotropic feedback due to high-frequency eddies. J. Atmos. Sci., 48, 1141-1159.

Michelangeli, P. A., R. Vautard, and B. Legras, 1995: Weather regimes: Recurrence and quasi stationarity. J. Atmos. Sci., 52, $1237-1256$.

Mo, K. C., and M. Ghil, 1988: Cluster analysis of multiple planetary flow regimes. J. Geophys. Res., 93 D, $10927-10952$.

Molteni, F., S. Tibaldi, and T. N. Palmer, 1990: Regimes in the wintertime extratropical circulation. I: Observational evidence. Quart. J. Roy. Meteor. Soc., 116, 31-67.

Moron, V., R. Vautard, and M. Ghil, 1998: Trends, interdecadal and interannual oscillations in the global sea-surface temperature. Climate Dyn., 14, 545-569. 
Palmer, T. N., 1993: Extended-range prediction and the Lorenz model. Bull. Amer. Meteor. Soc., 74, 49-65.

- , and Z. Sun, 1985: A modeling and observational study of the relationship between sea surface temperature in the north-west Atlantic and the atmospheric general circulation. Quart. J. Roy. Meteor. Soc., 111, 947-975.

Peng, S., L. A. Mysak, H. Ritchie, J. Derome, and B. Dugas, 1995: The differences between early and midwinter atmospheric responses to sea surface temperature anomalies in the northwest Atlantic. J. Climate, 8, 137-157.

Rheinhold, B. B., and R. T. Pierrehumbert, 1982: Dynamics of weather regimes: Quasi-stationary waves and blocking. Mon. Wea. Rev., 110, 1105-1145.

Robertson, A. W., and W. Metz, 1990: Transient-eddy feedbacks derived from linear theory and observations. J. Atmos. Sci., 47, 2743-2764.

—, and M. Ghil, 1999: Large-scale weather regimes and local climate over the western United States. J. Climate, 12, 17961813.

, - - and M. Latif, 1998: Decadal variability in North Atlantic weather regimes. ACCP Notes, 5 (1), 1-3.
Roeckner E., and Coauthors, 1992: Simulation of the present-day climate with the ECHAM model: Impact of model physics and resolution. Rep. 93, Max-Planck-Institut für Meteorologie, Hamburg, Germany, 171 pp. [Available from Max-Planck-Institut für Meteorologie, Bundesstrasse 55, 20146 Hamburg, Germany.]

Smyth, P., K. Ide, and M. Ghil, 1999: Multiple regimes in Northern Hemisphere height fields via mixture model clustering. J. Atmos. Sci., 56, 3704-3723.

Thompson, W. J., and J. M. Wallace, 1998: The Arctic Oscillation signature in the wintertime geopotential height and temperature fields. Geophys. Res. Lett., 25, 1297-1300.

Vautard, R., 1990: Multiple weather regimes over the North Atlantic: Analysis of precursors and successors. Mon. Wea. Rev., 118, 2056-2081.

— K. C. Mo, and M. Ghil, 1990: Statistical significance test for transition matrices of atmospheric Markov chains. J. Atmos. Sci., 47, 1926-1931.

Wallace, J. M., C. Smith, and Q. Jiang, 1990: Spatial patterns of atmosphere-ocean interaction in the northern winter. J. Climate, 3, 990-998. 